Riga Teacher Training and Educational Management Academy, Latvia

University of Applied Management, Erding, Germany

\title{
DOES COGNITIVE TRAINING MAKE NUTRITION AND EXERCISE PROGRAMS FOR WEIGHT REDUCTION MORE SUCCESSFUL?
}

\begin{abstract}
By carrying out an intervention study including a two-month period of executing measures and an observation period of another two months, the hypothesis stating that cognitive training makes weight reduction programs more successful is to be confirmed. The measures are introduced in a fitness facility. This study involved a cooperation with Mrs. Sporty. The target group are overweight women from the age of 30 onwards. From this target group of overweight women from the age of 30 onwards, three groups of 25 participants each are randomized. Two groups of 25 participants each are assembled from various Mrs. Sporty facilities in Flensburg, Schleswig, Rendsburg, and Husum. A third group of overweight non-athletes is generated over the press, flyers, and posters. All groups equally take part in one or, if required, two introductory individual interviews at the beginning in which initial data is gathered by way of a questionnaire that was developed for the study and first measurements are taken regarding BMI, waist size, and body fat content. Moreover, the participants 'individual situation and their specific problems are discussed and the intervention is adjusted accordingly. For participants that also receive cognitive training, mental measures that are in accordance with the concept developed and presented for the study are additionally integrated in the interviews as well as in the questionnaire and conducted theoretically and practically throughout the entire procedure.
\end{abstract}

Keywords: cognitive training, weight reduction, nutrition, and exercise

\section{INTRODUCTION}

Health, health promotion, prevention - these guiding terms from interdisciplinary health research have grown into the everyday life of the population long ago and pave the way for a necessary development: to finally and successfully hold off the increasing health risk factors of the modern world such as overweight, lack of exercise, and stress and to counter them with effective methods (Marcus et al., 2000; Wallace, White, Downie, Dalzell \& Doran, 1993). Furthermore, there is lack of a certain minimum of activity; therefore, it is recommended that adults should moderately-intensively exercise for at least 30 minutes at least three times a week or be alternatively active (Haskell, Russel, Powell, Blair \& Franklin, 2007). The data of the last population-representative Federal Health Survey show very sobering results: only $13 \%$ of the German adults fulfill the necessary minimum of physical activity (Mensink, 2003). These problems occur to us in many forms and shapes, whether in the working world or in private life; modern life's developments and demands leave traces all over one's body, mind, and soul, which increasingly leads to conditions that require treatment. Be it, for example, back problems due to overstraining conditions as well as lack of movement in the workplace, psychological distress caused by increasingly higher demands and resulting in further medical conditions, or also private life which is more and more shaped by inactivity and entered by overweight, posture problems, 
general discontent, and much more - many figures of numerous studies on this topic are sounding the alarm; several things have been tried; health management in public and professional life has been legally consolidated but successful results are not yet visible everywhere. One of the greatest and most difficult problems concerning health in the population certainly is the risk factor of overweight which will be focused on in this work. Overweight and the associated risks and medical conditions in this country are increasing and Germany has the image of being the "country of the fat No. 1" with 75 per cent of men and 59 per cent of women being overweight as was documented, for example, by the International Association for the Study of Obesity and in the study results of the European Agency for Statistics (International Association for the Study of Obesity, 2007). A highly topical study stating that only one in seven Germans lives healthily is making health experts sound the alarm: German citizens have bad eating habits and do not exercise enough. Not even 14 per cent of them live as healthily as would be good for them; this is shown in a study by the DKV and the Center for Health at the German Sport University of Cologne that was only recently presented in Berlin. The study launched by the private health insurance DKV especially named lack of exercise and inadequate nutrition as the main deficits: According to the results of this study, every second person does not follow a balanced diet; and every third person does not consume fruits and vegetables on a daily basis (DKV/DSHS, 2010). Numerous efforts are being made and there are, without a doubt, also good successes in the area of nutrition and exercise in which programs have led to weight reduction (Diaetprogramme, 2013). Be it reduction programs by, for example PlusOne or the DGE; be it diets such as fasting cures, formula diets, Glyx, low-fat or low-carb diets, food combining, mixed food, and many more; or be it also accompanying modern supporting software programs such as PRODI, Nutri Guide, DGE pc, EBIS pro, and ERNA (Diaetprogramme, 2013) - all of these measures somehow bring about a certain success since they more or less effectively lead to weight loss; and yet the problem does not seem to be solved according to the alarming latest figures relating to overweight. For how do things stand with sustainability? For how long do people actually stay slim after having successfully lost weight? There is an immense lack of sustainability here because only very few people manage to maintain their weight after it has been successfully reduced. Why is that? Many years of experience gained during author's work with weight reduction programs in the area of nutrition and exercise have shown that it does not suffice to move people and to convey knowledge of healthy nutrition. By perceiving the human being in his entireness as an entity of body, mind, and soul, two components can be certainly reached of his entity through exercise and nutrition: his body since author's program moves him; and his mind since author teaches him what to eat. An overweight person most certainly loses weight by that. However, it must also be succeeded in reaching a person's soul. They have to actually want to do what they are doing. They have to decide by themselves and be convinced of their own decision. They have to possess the necessary amount of self-efficacy. Only then can a person stay slim.

\section{THE AIM OF THE STUDY}

The aim of the study is to research if cognitive training program developed by the author makes weight reduction programs more successful by carrying out an intervention study including a two-month period of executing measures and an observation period of another two months.

\section{MATERIALS AND METHODS}

The measures are introduced in a fitness facility. Hypothesis 1: Experimental group "Exercise and Nutrition" - The results shall prove that all of the participants of the experimental group "Exercise and Nutrition" can successfully reduce their weight during the study period of 
four months, but that they only exhibit little change in consciousness. Hypothesis 2: Experimental group "Exercise, Nutrition, Cognitive Training" - The participants of the experimental group that received cognitive training in addition to the Mrs. Sporty exercise and nutrition program shall exhibit better results regarding the tested variables throughout the study. Moreover, after having taken the measure, a significant change in consciousness as well as a clear and confident change in behavior shall be the result during the cognitive query. Hypothesis 3: The control group cognitive training - shall emphasize once more the benefits of cognitive measures, i.e. that there is a change in consciousness after the process of the measure.

The sample consists of three randomly gathered groups of 25 overweight (BMI >26) participants each. Two of these groups (experimental groups) are assembled from the Mrs. Sporty sports facilities. A third group (control group) is generated outside of these facilities over the press, flyers, and posters. Each one of the three groups receives a different program of measures. The third group, i.e. the control group, consisting of overweight non-athletes that only receive cognitive training was chosen deliberately. The hypothesis for this group is that cognitive training alone already suffices to evoke those changes in consciousness in a person that are necessary for lasting successes in life, that is, for weight reduction in this case. As a result, it is expected that the third group will be animated by cognitive training to take matters into their own hands concerning their weight problem and to independently and confidently embark on a path towards the goals they had set. The survey instruments include the determination of the Body Mass Index (BMI) and the values of waist size as well as the measurement of body fat. The measurement of the cognitive values is done via questionnaires about the query on consciousness and behavioral patterns before the measure has been introduced, as well as after the following two-month observation period. The accompanying cognitive concept is a new one that has been developed from various approaches. Since the cognitive concept and its expected influence on the measure is the core element of this work, it will be briefly presented in the following. The accompanying cognitive concept that is applied here is based on various scientific approaches or models. Thus, the salutogenesis model by Antonovsky (1997), the transtheoretical model by Prochaska and DiClemente (Prochaska et al., 1997), the MindConcept by Decker (1999, 2003, 2010), the query of self-efficacy by Schwarzer (2002), and the TETA principles of action form the basis of the concept used in the context of this study. The cognitive concept consists of the following: introduction to the concept (presentation); opening access to the unconscious (exercise); phase of concrete problem clarification (conversation); phase of goal clarification (conversation); query of perceived self-efficacy (questionnaire); implementation of various measures (exercise/ questionnaire); another query of perceived self-efficacy (questionnaire).

\section{RESULTS}

The data gathered from this study have shown a clear tendency towards the expected results in the initial statistical evaluation. At first, a general overview will be given on what was discovered in the individual groups, followed by a detailed description of the individual statistically collected data:

\section{Experimental group "Exercise and Nutrition" - Hypothesis 1}

The evaluation of the results showed that all the participants of the experimental group "Exercise and Nutrition" were able to successfully reduce their weight during the four-month study period. However, the query of self-efficacy did not lead to a significant change in consciousness regarding their problematic behavior after the observation period of eight weeks that followed the measure, which triggers the risk that a lot of the participants could regain their weight over time. 
Another measurement after a long period of time of, for example, a year thereof will probably show promising results which would emphasize the significance of cognitive training once more. Due to their minimal change in consciousness, this experimental group "Exercise and Nutrition" turns out to be a group suitable for the subsequent motivational measure. The first part of the hypothesis saying that this group will successfully lose weight could be confirmed so far. The second part of the hypothesis saying that this group will not be able to maintain the weight they have reached will probably be confirmed in the following period of the study.

\section{Experimental group "Exercise, Nutrition, Cognitive Training” - Hypothesis 2}

The participants of the experimental group that received cognitive training in addition to the Mrs. Sporty exercise and nutrition program actually achieved better results regarding the tested variables during the study. After the measure, the cognitive query of self-efficacy showed a significant change in consciousness as well as a clear and confident change in behavior. The hypothesis drawn up for this group could be confirmed so far.

\section{Control group "Cognitive Training" - Hypothesis 3}

The evaluation of the results for the control group also demonstrated the very clear benefits of cognitive measures. In the process of the measure, a great change in consciousness was shown by nearly all of the participants that regarded their overweight as a life problem. There were only minor deviations; however, those only occurred among the participants that, despite their overweight, were satisfied with themselves and their lives and did not see the necessity of change. Among all the other participants, significantly increased self-efficacy as well as visible change of behavior and even weight loss were observed although no measures of nutrition or exercise were taken at all. The participants had started to reshape life by themselves because they had successfully relearned by means of the mental measures. Therefore, the third hypothesis can be confirmed as well. First, however, the measurable results according to SPSS shall be presented in numbers. The detailed results regarding the significance of the tested variables showed promising evidence concerning the question of this study and the associated hypotheses. In the following, the statistical evaluation of the individual variables according to the SPSS program and the corresponding precise numbers will be presented.

The loss of body weight shows clear and indicatory results in the statistical data. It should be noted that the loss of body weight is not the same as the loss of body fat. The loss of body weight also includes the normal loss of water that goes along with fat reduction; this is why more visible values can be expected than by merely regarding the body fat values. This becomes evident in comparison to the body fat evaluation. Expressed in figures, the following has been revealed in the groups with reference to their weight: Group $1 \mathrm{E}, \mathrm{B}(\mathrm{M}=1.000, \mathrm{SD}=1.280)$; Group $2 \mathrm{E}, \mathrm{B}, \mathrm{kT}$ $(\mathrm{M}=2.352, \mathrm{SD}=1.674)$; Group $3 \mathrm{kT}(\mathrm{M}=1.304, \mathrm{SD}=1.436)$; $(\mathrm{E}=$ nutrition; $\mathrm{B}=$ exercise; $\mathrm{kT}=$ cognitive training; $\mathrm{M}=$ mean value; $\mathrm{SD}=$ standard deviation). The mean values for the individual groups indicate the weight loss in kilograms. Therefore, group 1 lost $1 \mathrm{~kg}$ on average, group 2 lost $2.3 \mathrm{~kg}$ and group 3 lost $1.3 \mathrm{~kg}$. It becomes clear that the combination of nutrition, exercise, and cognitive training could trigger the greatest weight loss and that even the control group which was only assisted mentally could achieve a greater weight loss than the nutrition and exercise group. Sense and value of the third control group are already justified here since the effectiveness of mental measures is clearly emphasized. For graphical illustration of the data, the weight loss in the individual groups will be displayed in the form of a bar chart (see Picture 1). 
Picture 1. Bar chart of weight loss after four weeks (own diagram based on SPSS)

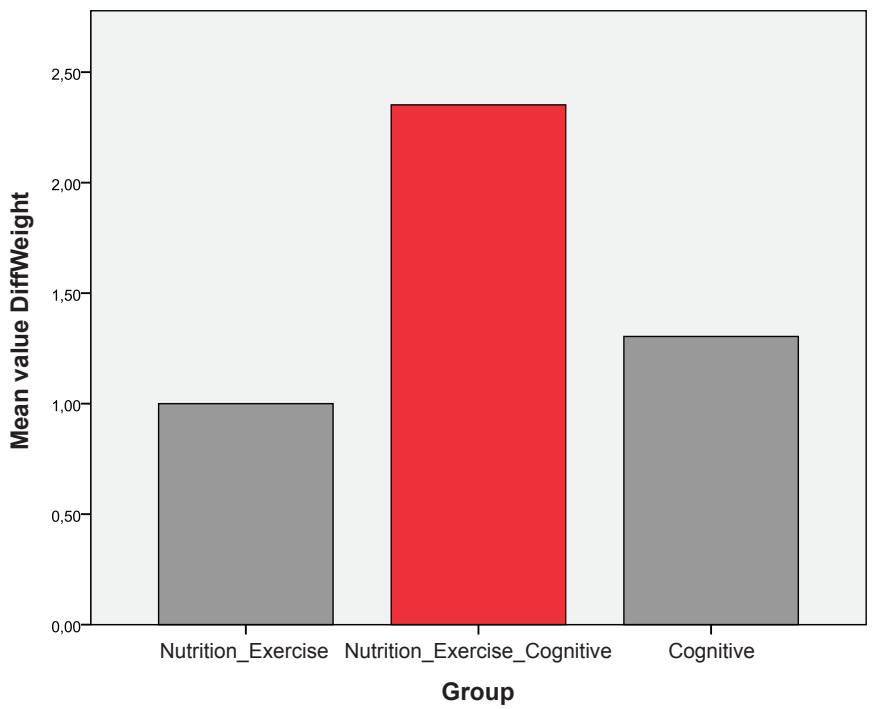

The evaluation of the Body Mass Index results was, on the whole, significant with regard to the question as well. The numbers of the evaluation are as follows: Group $1 \mathrm{E}, \mathrm{B}(\mathrm{M}=0.356$, $\mathrm{SD}=0.463)$; Group $2 \mathrm{E}, \mathrm{B}, \mathrm{kT}(\mathrm{M}=0.838, \mathrm{SD}=0.617)$; Group $3 \mathrm{kT}(\mathrm{M}=0.464, \mathrm{SD}=0.492)$; ( $\mathrm{E}=$ nutrition; $\mathrm{B}=$ exercise; $\mathrm{kt}=$ cognitive training; $\mathrm{M}=$ mean value; $\mathrm{SD}=$ standard deviation). The mean value represents a calculation between the pre-value and the post-value. Here group 2 also demonstrated the strongest result; and control group 3 again shows a bigger success than group 1 . The results for the individual groups will once again be graphically represented in a bar chart (see Picture 2).

Picture 2. Bar chart of BMI after four weeks (own diagram based on SPSS)

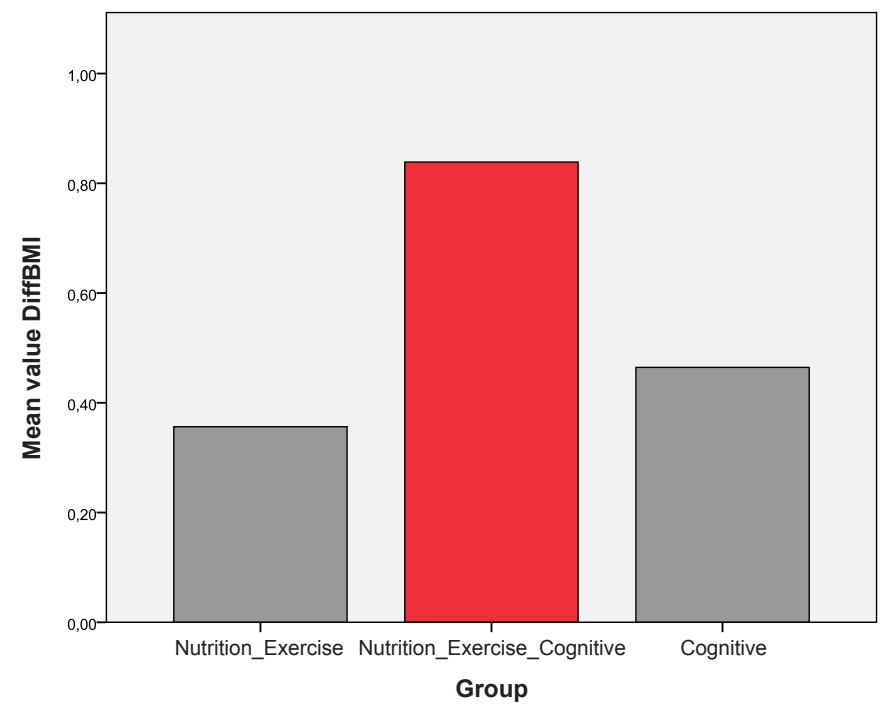


The outliers that occurred under considered normal distribution are also presented in another figure. The value statistics concerning the waist size produced significant numbers as well that are as follows: Group $1 \mathrm{E}, \mathrm{B}(\mathrm{M}=3.044, \mathrm{SD}=2.392)$; Group $2 \mathrm{E}, \mathrm{B}, \mathrm{kT}(\mathrm{M}=4.136$, $\mathrm{SD}=2.322)$; Group $3 \mathrm{kT}(\mathrm{M}=1.908, \mathrm{SD}=2.123)$; $(\mathrm{E}=$ nutrition; $\mathrm{B}=$ exercise; $\mathrm{kT}=$ cognitive training; $\mathrm{M}=$ mean value; $\mathrm{SD}=$ standard deviation). The mean value of, for example, 3.044 is at $3 \mathrm{~cm}$. Concerning significance, it appears that group 2 is superior to group 1 regarding their results; and the control group was also able to achieve a reduction in waist size of almost $2 \mathrm{~cm}$. Once again, a graphical representation of the results for the individual groups are given by using a bar chart (see Picture 3):

\section{Picture 3. Bar chart of waist (own diagram based on SPSS)}

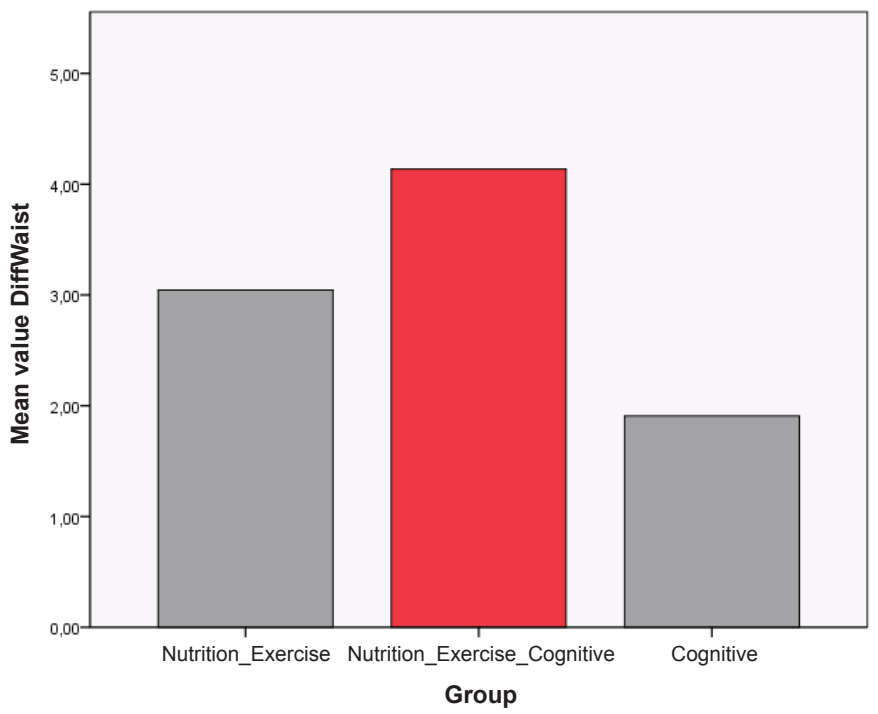

The body fat evaluation of the measurement that was performed with the aid of a handheld meter was, on the whole, not of great relevance for this study because the study period was not long enough for this variable to actually achieve considerable significance. Yet, this small development can still be regarded as a guiding criterion. In a temporally more extensive study - as has already been started -, far more clear results could by all means be expected. In the following, the descriptive statistics for the individual groups will be expressed in figures: Group $1 \mathrm{E}, \mathrm{B}(\mathrm{M}=0.008, \mathrm{SD}=0.015)$; Group $2 \mathrm{E}, \mathrm{B}, \mathrm{kT}(\mathrm{M}=0.018$, $\mathrm{SD}=0.017)$; Group $3 \mathrm{kT}(\mathrm{M}=$ $0.012, \mathrm{SD}=0.018) ;(\mathrm{E}=$ nutrition; $\mathrm{B}=$ exercise $\mathrm{kT}=$ cognitive training; $\mathrm{M}=$ mean value; $\mathrm{SD}$ $=$ standard deviation). The determined mean values $(\mathrm{M})$ express in percentages that during the period of measures 8 per cent of fat was reduced in group 1, 18 per cent in group 2, and 12 per cent in group 3.

\section{CONCLUSIONS}

This study did not only show that cognitive training does actually make weight reduction programs more successful. Moreover, the key point became apparent stating that the individual himself is at the center of successful action equipped with his intrinsic motivation, his conviction and his strong will to achieve a set goal. It is the challenging task of the salutogenetically oriented 
cognitive training to restore and revive these strengths and resources in man at a time that is - as discussed in the introductory words on the problem at the beginning - shaped by stress, hectic, lack of movement, and all of the mentioned diseases of civilization.

The elaborations above have shown that the individual definitely has the desire to lead a self-determined life on his own responsibility. It is not very surprising that at times like these, it is not easy for the individual to have the ability to realize and shape his life in such a selfdetermined way. The wide range of stimuli, demands, impressions, and changes in everyday life inevitably leads to exhaustion and resignation. Even in all the other difficult circumstances, cognitive training, as was successfully implemented here in the area of weight reduction, offers a way out of excessive demands and helplessness towards good objectives, zest for life, and balance. For if one succeeds in giving people back their self-efficacy, that is, their conviction that they can achieve the goals that are meaningful to them through their own resources, some of the problems of civilization are well on the way to being solved.

In the progress of the work, it would be worth considering whether further research should be undertaken in the context of a study including a greater period of time and a higher number of participants, which would support the results and could demonstrate that the use of cognitive measures does not only enhance the success of weight reduction programs but also make it more sustainable. Furthermore, it makes sense to develop measures for other target groups. It should be taken into account here that men and children as well as adolescents are to be supervised differently in studies on these topics.

Moreover, it is worth considering whether cognitive concepts should be added to already existing nutrition and exercise programs in commercial fitness facilities and whether such offerings in other institutions should as well be extended this way.

With their special features, commercial health facilities as a destination for exercise, nutrition counseling, and weight reduction offer promising opportunities for health promotion. In this work, the manifold variations with regard to the offering and realization of nutrition and health counseling including mental forms were presented; furthermore, the existing interest of an expanding area of a private-sector leisure industry in health-promoting programs was shown. In a structural analysis of selected fitness studios in the city and in the Kiel area that preceded this study, the question was clarified to what extent they are suitable to offer health counseling that is planned in such a way. The existing and the intended offering structures in the areas of nutrition, exercise, and relaxation as well as customer potential and the interest of studio owners meet all the requirements for a corresponding multidimensional and interdisciplinary counseling concept (Lauch, 1998). The selection of the comprehensive methods and instruments of analysis must thereby be explained according to the central questions and determining factors that were formulated beforehand.

\section{REFERENCES}

Antonovsky, A. (1997). Salutogenese: Zur Entmystifizierung der Gesundheit [Salutogenesis: About the demystification of health]. A. Franke (Hrsg.), Deutsche Gesellschaft für Verhaltenstherapie [German Association for Behavior Therapy]. Tübingen: Dgvt-Verlag. (in German).

Decker, F. (1999). Alles beginnt im Kopf [Everything begins in the head]. Lexika Verlag. (in German).

Decker, F. (2003). Erfolgreich sein Leben meistern [Successfully mastering life]. Via Nova Verlag. (in German). 
Decker, F. (2010). Die Kunst gesund zu leben [The art of healthy living]. Via Nova Verlag. (in German).

Diaetprogramme (2013). Retrieved 06.06.2013 from http://www.sellpage.de/adipositas/frset_diaetprogramme. htm.

DKV/DSHS (2010). DKV-Report „Wie gesund lebt Deutschland?“. Kurzvorstellung der Ergebnisse [How healthy does Germany live? A brief overview of the results]. Köln: Zentrum für Gesundheit der Deutschen Sporthochschule. (in German).

Haskell, W. L., Lee, I. M., Russel, R. P., Powell, K. E., Blair, S. N. \& Franklin, B. A. (2007). Physical activity and health: Update recommendation for adults from the American college of sports medicine and the American heart association. Circulation, 116, 1081-1093.

IASO (2007). International Association for the Study of Obesity: Adult over-weight and obesity in the European Union (EU25). Retrieved 06.06.2013 from http://www.iotf.org/documents/Europeandatatable_000. $\underline{\mathrm{pdf}}$

Lauch, S. (1998). Strukturanalyse ausgewählter Fitness-Studios in der Stadt und im Raum Gießen unter besonderer Betrachtung einer möglichen Institutionalisierung von Gesundheitsberatung mit dem Schwerpunkt Ernährung. Unveröffentlichte Diplomarbeit des Instituts für Ernährungswissenschaft der Justus-Liebig-Universität Gießen [Structural analysis of selected gyms in the city and in the area of Gießen with particular attention on a possible institutionalization of health counseling with focus on nutrition]. (in German).

Marcus, B. H., et al. (2000). Physical activity behavior change: Issues in adoption and maintenance. Health Psychology, 19, 32-41.

Mensink, G. (2003). Bundes-Gesundheitssurvey: Körperliche Aktivität. Beiträge zur Gesundheitsberichterstattung des Bundes [Federal Health Survey: Physical activity. Contributions to the federal health monitoring system]. Berlin: Robert Koch-Institut. (in German).

Prochaska, J. O., Norcross, J. C., di Clemente, C. C. (1997). Jetzt fange ich neu an [Now I am making a new start]. München: Droemersche Verlagsanstalt. (in German).

Schwarzer, R., Jerusalem, M. (2002). Das Konzept der Selbstwirksamkeit. Zeitschrift für Pädagogik, 44. Beiheft: Selbstwirksamkeit und Motivationsprozesse in Bildungsinstitutionen [The concept of self-efficacy. Journal of pedagogy, appendix: Self-efficacy and motivational processes in educational institutions], 28-53. (in German).

Schwarzer, R., Jerusalem, M. (Hrsg.) (1999). Allgemeine Selbstwirksamkeitserwartung. Skalen zur Erfassung von Lehrer- und Schülermerkmalen. Dokumentation der psychometrischen Verfahren im Rahmen der Wissenschaftlichen Begleitung des Modellversuchs Selbstwirksame Schulen [General expectation of self-efficacy. Scales for measuring characteristics of teachers and students. Documentation of psychometric measures within the scope of the scientific monitoring of the model experiment 'Selfeffective schools']. Berlin: Freie Universität. (in German).

Wallace, E. S., White, J. A., Downie, A., Dalzell, G. W. N. \& Doran, D. (1993) Influence of exercise adherence level on modifiable coronary heart disease risk factors and functional-fitness levels in middle-aged men. British Journal of Sports Medicine, 27, 101-106.

\author{
René Paasch \\ RPIVA Doctoral Program of Pedagogy \\ Riga Teacher Training and Educational Management Academy, Latvia \\ University of Applied Management, Erding, Germany \\ Address: 24870 Ellingstedt, Op de Wohm 14, Germany \\ Phone: +49 4627-185709 \\ E-mail: info@renepaasch.de
}

